\title{
Micropropagation of black locust (Robinia pseudoacacia L.) and genetic stability of long term cultivated plants
}

\author{
Iwona Szyp-Borowska ${ }^{1} \bowtie$, Catarina Banha ${ }^{2}$, Tomasz Wojda ${ }^{1}$, Krystyna Szczygiet $^{1}$ \\ ${ }^{1}$ Forest Research Institute, Department of Silviculture and Genetics of Forest Trees, Sẹkocin Stary, Braci Leśnej 3, \\ 05-090 Raszyn, Poland, phone: +48 22 7150481, e-mail: I.Szyp@ibles.waw.pl \\ ${ }^{2}$ Instituto Politécnico de Coimbra, Escola Superior Agrária, Bencanta, 3045-601 Coimbra, Portugal
}

\section{Abstract}

The study on the in vitro micropropagation of Robinia pseudoacacia L. shows the possibility of the rapid increase of the vegetative progeny using organogenesis. The culture system consists of sequential use of three media, namely, the initiation medium (MS medium supplemented with $0.6 \mathrm{mg} \cdot 1^{-1} 6$-BA (6-benzylamino-purine), $0.1 \mathrm{mg} \cdot 1^{-1} \mathrm{NAA}$ (naphthalene acetic acid), proliferation medium (1/2 MS medium added with $1 \mathrm{mg} \cdot \mathrm{l}^{-1} 6-\mathrm{BA}$,) and root-induction medium (1/2 MS medium fortified with $\left.0.2 \mathrm{mg} \cdot 1^{-1} \mathrm{NAA}\right)$. The resulting micropropagated plants, fully acclimatised to an in vivo environment, did not show any visually detectable morphological variation.

In addition, we investigated the genetic stability (vegetative progeny to the donor plant) of a sample of 30 plants randomly taken from ca. 1067 micropropagated plants, by using three microsatellites loci Rops 15, Rops 16, Rops 18. Our results suggest that DNA sequence variations may occur in micropropagated plants.

\section{KeY WORDS}

black locust, micropropagation, microsatellites, genetic stability, tissue cultures

\section{INTRODUCTION}

Black locust (Robinia pseudoacacia L.) is a droughtresistant tree and, in symbiosis with Rhizobium, able to fix dinitrogen from the atmosphere. It is, therefore, an interesting species for marginal lands where soil amelioration is sought in addition to economic gain. Robinia is widely planted due to its rapid growth and ecological plasticity, adaptability and good timber quality.

Several countries have started research programmes on improving black locust wood quality and/or increasing production of biomass for energy purpose. Future directions for forestry research in Poland include this species suitable for production of the small-sized timber in short production cycles as an attractive, renewable energy resource. As a result of the latest study conducted by the Forest Research Institute, a few forest stands with black locust characterised by the unique, straight form of the stem have been localised. Therefore, root microcuttings from the selected straight stem trees were collected from those stands and these trees became the basis of the most valuable forest stands of the black locust in Poland. However, there are individual genotypes that are resistant to the efforts of propagation by the traditional methods. In this context, the black locust issue demands the development of an effective method of 
micropropagation to enable the production of vegetative microcuttings on a commercial scale.

Several reports have showed that in vitro propagation of $R$. pseudoacacia is a feasible method to produce large numbers of clonal plants (Enescu and Jucan 1985; Balla and Vértesy 1985; Barghchi 1987; Arrillaga 1993; Zhang et al. 2007; Rédei et al. 2013). To obtain effective procedures of in vitro propagation, authors have tested two main factors: the type of explants and the type and concentration of plant growth regulators. Unfortunately, it is well known that exogenous hormones and growth regulators useful for the micropropagation, especially the synthetic ones, have been a cause of genetic instability (Martin et al. 2006). Even at optimal levels, long-term multiplication may often lead to somaclonal or epigenetic variations in the micropropagated plants questioning the very fidelity of their clonal nature. Therefore, it is necessary to establish genetic uniformity of micropropagated shoots by molecular techniques that would enable a highly sensitive detection of any mutations.

Random amplified polymorphic DNA markers (RAPDs) have been applied to determine the genetic homogeneity in a small sample of micropropagated 4-year-old plants of $R$. pseudoacacia (Bindiya and Kanwar 2003). The aim of this study was to assess the possibility to apply microsatellite fingerprinting technology for checking genetic stability of black locust tissue-culture derived plantlets. Microsatellites, comprising tandemly repeated short nucleotide sequences, are found as ubiquitous, abundant and highly polymorphic in eukaryotic genomes. Mutation rates are estimated to occur between $10^{-2}$ and $10^{-6}$ events per locus per generation, which are very high compared to point mutation rates at coding gene loci (Li et al. 2002). Tree microsatellite loci (Rops 15, Rops 16, Rops 18) with a hypervariable dinucleotide repeat locus (AG motif) and with an extraordinarily high mutation rate were used by Lian and coworkers (2004), in study on mutational characteristics of black locust in different leaf samples from individual ramets, ramets within individual genets and seeds from individual mother ramets.

The following work covers the results of trying to obtain planting stock of $R$. pseudoacacia using vegetative reproduction in the in vitro tissue cultures. We have also monitored the genetic stability of long-term micropropagated shoots of black locust clones using microsatellite loci Rops 15, Rops 16, Rops 18 . Our results suggest that microsatellite technique can be successfully used to assess genetic variations in micropropagated plants.

\section{Material AND methods}

\section{Plant material}

As the starting material for micropropagation, the fragments of shoots from plus trees, and from clones originating from seed orchard were used (Tab. 1). The young shoots that sprouted from the lower trunk were collected in spring, before budding.

Table 1. List of propagated clones of Robinia pseudoacacia

\begin{tabular}{|c|l|c|}
\hline Name & \multicolumn{1}{|c|}{ Clones number } & $\begin{array}{c}\text { No of seedlings } \\
\text { from in vitro }\end{array}$ \\
\hline $1 \mathrm{PN}$ & 9733 (root cuttinngs) & 2 \\
\hline $2 \mathrm{PN}$ & 9755 ( grafted) & 265 \\
\hline $3 \mathrm{PN}$ & 9759 ( grafted) & 68 \\
\hline $4 \mathrm{PN}$ & 9757 ( root cuttinngs) & 247 \\
\hline $5 \mathrm{PN}$ & 9733 (grafted) & 43 \\
\hline $6 \mathrm{PN}$ & 9735 (grafted) & 80 \\
\hline $7 \mathrm{PN}$ & 9758 (grafted) & 212 \\
\hline $8 \mathrm{PN}$ & 9759 (grafted) & 11 \\
\hline $10 \mathrm{DM}$ & 9755 (plus tree) & 139 \\
\hline
\end{tabular}

\section{Culture medium and incubation conditions}

In order to initiate the cultures, the sterilised material was laid out on the MS culture medium (Murashige and Skoog 1962) for initiation. The composition of the initiation medium was as describer in Table 2. The first week after the cultures initiation, they were kept in phytotron in the darkness and then exposed to the 16-hour photoperiod of the daily temperature of $25^{\circ} \mathrm{C}$ and the night temperature of $20^{\circ} \mathrm{C}$. To keep the cultures in vigorous growth, the subcultures were laid out on the fresh culture medium every 14 days. The emerging adventitious shoots about $1.5-3 \mathrm{~cm}$ long were cut and allocated up to rooting or secondary propagation (secondary explants).

\section{Proliferation and rooting}

Secondary explants were put on the MS culture medium diluted by half $(1 / 2 \mathrm{MS})$, supplemented with higher concentration of cytokines $-1 \mathrm{mg} \cdot \mathrm{l}^{-1}$ BAP. Shoots allocated up to rooting were first kept for 1 week on the culture 
medium enhanced with auxins and then for $4-5$ weeks laid out to root on the $1 / 2$ MS culture medium without the growth hormones and supplemented with activated carbon $2 \mathrm{~g} \cdot \mathrm{H}^{-1}$ (Tab. 2).

Table 2. The composition of the culture medium for vegetative propagation of Robinia pseudoacacia

\begin{tabular}{|l|c|c|c|}
\hline \multicolumn{1}{|c|}{ Compounds } & Initiation & $\begin{array}{c}\text { Prolife- } \\
\text { ration }\end{array}$ & $\begin{array}{c}\text { Induction } \\
\text { of roots }\end{array}$ \\
\hline MS medium & $\begin{array}{c}\text { full } \\
\text { strength* }\end{array}$ & $\begin{array}{c}\text { half } \\
\text { strength* }\end{array}$ & $\begin{array}{c}\text { half } \\
\text { strength* }\end{array}$ \\
\hline Sucrose $\left(\mathrm{g} \cdot \mathrm{r}^{-1}\right)$ & 30.0 & 30.0 & 20.0 \\
\hline Agar $\left(\mathrm{g} \cdot \mathrm{r}^{-1}\right)$ & 5.5 & 5.5 & 5.5 \\
\hline BAP $\left(\mathrm{mg} \cdot \mathrm{r}^{-1}\right)$ & 0.6 & 1.0 & - \\
\hline NAA $\left(\mathrm{mg} \cdot \mathrm{r}^{-1}\right)$ & 0.1 & - & $(0.2)$ \\
\hline activated charcoal $\left(\mathrm{g} \cdot \mathrm{r}^{-1}\right)$ & - & - & 2.0 \\
\hline pH & 5.8 & 5.8 & 5.8 \\
\hline
\end{tabular}

${ }^{*}$ Half strength means the concentration of major element salts is halved.

NAA: naphthalene acetic acid; 6-BA: 6-benzylamino-purine;

IBA: 3 -indolebutyric acid.

\section{Greenhouse transfer}

Acclimation of the black locust clones occurs under greenhouse conditions. Adaptation of the plantlets grown in vitro to the growth in natural conditions required keeping the low intensity of light, high humidity of air and the temperature about $15-20^{\circ} \mathrm{C}$. In order to attain these conditions, jars with the rooted shoots were moved for 1-2 weeks to the greenhouse and afterwards, the plantlets were planted in the pots filled with the mixture of peat and perlite in the ratio 1:2 and covered with foil. After 7-10 days, the humidity of the air was gradually lowered. The microcuttings were cultivated in these conditions for about 3 months in the greenhouse and then put outside.

\section{Plant material for DNA extraction}

The fresh leaves from the mother plants (from clones and plus trees) were used as a source of DNA. For testing the long-term effects, 30 plantlets obtained after repeatedly sub-culturing in MS medium for 24 and 48 times (approximately 1 and 2 years) after 2 -week period were used. The DNA was extracted by using the DNeasy Plant Mini Kit (250) supplied by Qiagen.

\section{DNA amplification}

According to Lian et al. (2004), three microsatellites loci Rops 15, Rops 16, Rops 18 were used to describe genotypes of propagated black locust plant. The characteristics of these three microsatellites are listed in Table 3. Based on the observations of optimal annealing temperature for these markers, we composed the multiplex PCR. For the multiplex reaction, we used the Multiplex PCR kit (Qiagen). Concentrations of the primer pairs in the primer premix were $0.2-0.3 \mu \mathrm{M}$ of each designed primer pair. The cycling conditions for the multiplex were as follows: an initial step at $95^{\circ} \mathrm{C}$ for $15 \mathrm{~min}$; then 30 cycles at $94^{\circ} \mathrm{C}$ for $30 \mathrm{~s}, 55^{\circ} \mathrm{C}$ for $30 \mathrm{~s}$ and $72^{\circ} \mathrm{C}$ for $30 \mathrm{~s}$; and a final incubation at $70^{\circ} \mathrm{C}$ for $10 \mathrm{~min}$. The reaction products were fractionated using an CEQ 8800 $\left(\right.$ Beckman-Coulter $\left.{ }^{R}\right)$, sequencer.

\section{RESULTS}

The breeding cycle, from the initiation of the cultures, to the obtainment of the microseedlings capable of growth and development in the natural conditions and the growth of their first shoots, took 5-6 months (from April to September). However, the first microseedlings were planted only 4 months after the initiation of the cul-

Table 3. List of primers their annealing temperature $(\mathrm{Ta})$, sequences and size of the amplified fragment

\begin{tabular}{|c|c|c|c|c|c|c|}
\hline Locus & Repeat & Primer sequence $\left(5^{\prime}-3^{\prime}\right)$ & $\mathrm{Ta}\left({ }^{\circ} \mathrm{C}\right)$ & $\begin{array}{c}\text { Size range } \\
\text { (bp) }\end{array}$ & \begin{tabular}{|c|} 
No. \\
of alleles
\end{tabular} & $\begin{array}{c}\text { GenBank } \\
\text { accession no. }\end{array}$ \\
\hline \multirow{2}{*}{ Rops 15} & \multirow{2}{*}{$(\mathrm{CT})_{20}$} & GCCCATTTTCAAGAATCCATATATTGG & \multirow{2}{*}{54} & \multirow{2}{*}{$112-254$} & \multirow{2}{*}{43} & \multirow{2}{*}{ AB120731 } \\
\hline & & TCATCCTTGTTTTGGACAATC & & & & \\
\hline \multirow{2}{*}{ Rops 16} & \multirow{2}{*}{$(\mathrm{CT})_{13}$} & AACCCTAAAAGCCTCGTTATC & \multirow{2}{*}{56} & \multirow{2}{*}{$195-223$} & \multirow{2}{*}{15} & \multirow{2}{*}{ AB120732 } \\
\hline & & TGGCATTTTTTGGAAGACACC & & & & \\
\hline \multirow{2}{*}{ Rops 18} & \multirow{2}{*}{$(\mathrm{AC})_{8}$} & AGATAAGATCAAGTGCAAGAGTGTAAG & \multirow{2}{*}{54} & \multirow{2}{*}{$135-219$} & \multirow{2}{*}{13} & \multirow{2}{*}{ AB120733 } \\
\hline & & TAATCCTCGAGGGAACAATAC & & & & \\
\hline
\end{tabular}


tures. The difficulty of rooting of microcuttings caused the differences between the vegetative progeny obtained from the individual clones (Tab. 1). The most resistant clones were $1 \mathrm{PN}$ and $8 \mathrm{PN}$. The clones 2PN, 4PN, 7PN proliferated at a similar high rate. From 8 to 30, sometimes even more (uncountable) developing adventitious shoots on one explant were observed.

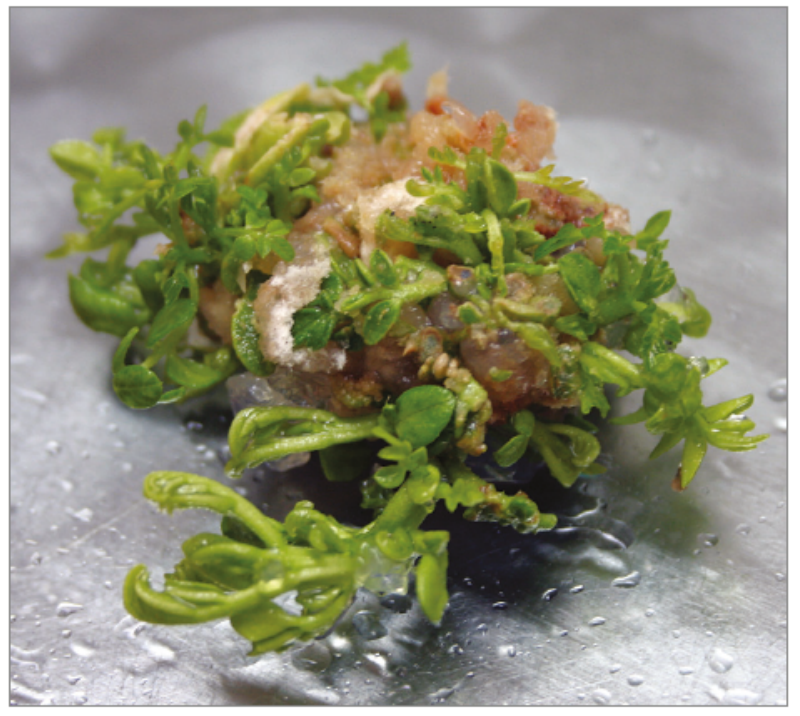

Figure 1. Multiplantlets of Robinia pseudoacacia

They formed so called multiplantlets (Fig. 1) from which the shoots for rooting were obtained. Rooting of the emerging shoots in June was very effective for the majority of clones, $89.5 \%$. The process of rooting of the adventitious shoots has taken about 4-5 weeks

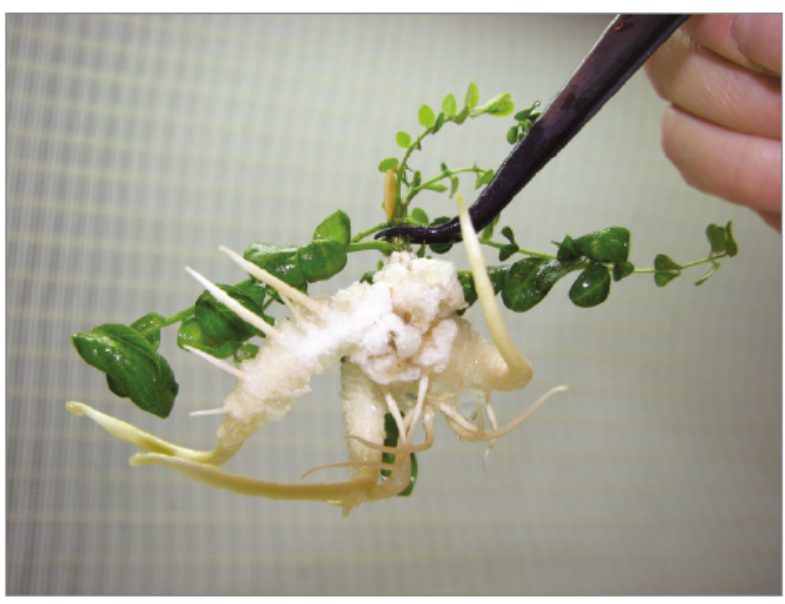

Figure 2. Root system on the adventitious shoot [MS culture medium from NAA-1-naphthaleneacetic acid $\left.\left(0.2 \mathrm{mg} \cdot \mathrm{r}^{-1}\right)\right]$ (phot. P. Markiewicz)

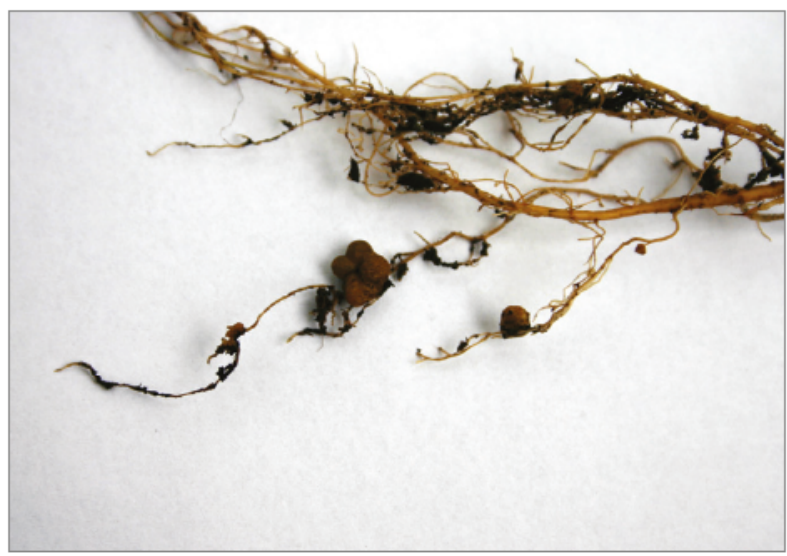

Figure 3. Root nodule grown on the Robinia pseudoacacia cuttings after planting them in the substrate
Table 4. Genotypes observed among seedlings obtained after repeated sub-culturing

\begin{tabular}{|c|c|c|c|c|c|c|}
\hline \multirow{2}{*}{$\begin{array}{c}\text { Clone } \\
\text { name }\end{array}$} & \multicolumn{6}{|c|}{ Genotypes (after 1 or 2 years) } \\
\cline { 2 - 7 } & \multicolumn{2}{|c|}{ Rops 15} & \multicolumn{2}{c|}{ Rops 16} & \multicolumn{2}{c|}{ Rops 18} \\
\hline 1PN & $126 / 162$ & & $162 / 204$ & $204 / 218(1,2)$ & $134 / 204$ & \\
\hline 2 PN & $126 / 144$ & & $204 / 218$ & & $134 / 210$ & \\
\hline $3 P N$ & $126 / 144$ & & $204 / 218$ & & $134 / 210$ & \\
\hline $4 P N$ & $126 / 144$ & & $204 / 218$ & & $134 / 210$ & \\
\hline $5 P N$ & $126 / 144$ & & $204 / 218$ & & $134 / 210$ & \\
\hline $6 P N$ & $118 / 144$ & & $206 / 212$ & & $136 / 210$ & \\
\hline $7 P N$ & $126 / 144$ & & $204 / 218$ & & $134 / 210$ & \\
\hline 8PN & $126 / 144$ & & $160 / 204$ & $204 / 204(2)$ & $134 / 204$ & $134 / 136(2)$ \\
\hline $10 \mathrm{DM}$ & $126 / 144$ & & $204 / 218$ & & $134 / 210$ & $134 / 218(1)$ \\
\hline
\end{tabular}

(Fig. 2). At the end of July, the seedlings were put outside the greenhouse to lignify before the winter period. We also observed characteristic root nodules on the roots of the grown seedlings. They grew as a result of overgrowth of the plant tissue invigorated by the nitrogen-fixing bacteria (mainly $\mathrm{AzO}$ tobacter) (Fig. 3). Those nodules grew independently, after planting the microcuttings in the mixture of peat and perlite.

Micropropagated plantlets of black locust that developed from axillary shoot bud explants over 1 and 2 years ago were screened for genetic variation. In order to confirm the genetic fidelity, a comparison of 
three microsatellites locus of 30 vegetative progeny of micropropagated plant and a control plant (donor plant) was carried out. Leaves obtained from different subclones rarely had different genotypes at the locus Rops 16 (only clone 1PN, 8PN) and Rops 18 (8PN, 10DM). Individual variations emerged both in the 1 st and 2 nd year of culturing. Clone 8PN study showed that mutations were identified in two loci (Tab. 4). In case of this clone, it was very difficult to obtain in vitro progeny and the quantity of clone 8PN was the lowest (Tab. 1).

\section{Discussion}

The technique of the in vitro culture of $R$. pseudoacacia is well established although in case of two clones, the rooting process required additional treatments. Transferring shoots to an auxin-free medium was beneficial for rooting. Admittedly, auxins have a rhizogenic action during the root induction phase and stimulate cells to engage in the establishment of meristemoids (Garrido et al. 2002), but the same phytohormones become inhibitory after $96 \mathrm{~h}$ and may arrest or inhibit growth of root primordia (De Klerk et al. 1999). Exposing the shoots to auxin for sufficient duration permitted root initiation, but inhibited further development. In our rooting procedure for $R$. pseudoacacia, we applied successfully the MS medium supplemented with activated charcoal. Our results are confirmed by Dumas and Monteuuis findings (1995). They observed that activated charcoal in the medium culture improves not only rooting rates, but also roots growth of Pinus pinaster. In the in vitro conditions, the activated charcoal is commonly used in tissue culture media. The effects of activated charcoal may generate a darkened environment; adsorption of undesirable/inhibitory substances; adsorption of growth regulators and other organic compounds, or the release of growth promoting substances present in or adsorbed by activated charcoal (Ahuja 1985; Dumas and Monteuuis 1995; Pan and Staden 1998).

True-to-type clonal fidelity is one of the most important prerequisites in the micropropagation. A major problem that can be encountered with the in vitro culture is the presence of somaclonal variation among sub-clones of one parental line arising as a direct consequence of in vitro culture of plant cells, tissues or organs. The exact cause of somaclonal variation in the in vitro cultures is still unknown, although it is believed that alterations in auxin-cytokinin concentrations and their ratio, duration of the in vitro culture, in vitro stress due to unnatural conditions, altered diurnal rhythm and nutritional conditions occurring together or independently are responsible (Modgil et al. 2005). Due to such reasons, morphological variations are probably a common feature as long as the shoot/plantlet cultures are under the in vitro conditions, in contrast to normal state when such plantlets are transferred to soil. In the case of black locust, though certain morphotypes were observed during routine multiplication as well. Development of different morphotypes during prolonged in vitro culturing was also observed by Ishii et al. 1987 and Goto et al. 1998 while they were working on micropropagated morphotypes of Pinus radiata and Pinus thunbergii, respectively. In these studies as well as in several other studies, the use of cytokinins, especially the exposure to BAP coupled with altered diurnal rhythm and continuous availability of high levels of nutrients have been noted to induce hyper-hydricity (otherwise known as vitrification phenomenon) and alterations in morphology. Cultured plant tissues are also known to undergo high levels of oxidative stress due to reactive oxygen species formed within the cells and the latter is known to cause DNA damage, including that of microsatellite instability (Jackson et al. 1998). In our study, primers with highly sensitive detection of mutations have been screened by using molecular markers. Since there were only infrequent changes in the genotypes observed in the tissue of culture plants as compared to that of a donor plant, we conclude that our micropropagation protocol for R. pseudoacacia can be carried out for a considerable length of time with verification of genetic instability. From the present study, it is clear that somaclonal DNA sequence variation is present in micropropagated plants of R. pseudoacacia. Similarly, Bindiya and Kanwar (2003) using RAPD technique, obtained differences between micropropagated plants of black locust after 4 years of subculturing. Similarity indices ranged from 0.86 to 0.96 . Major et al. (1998) reported similarity coefficients ranging from 0.51 to 0.95 between 12 tissue cultured samples of Robinia and suggested that this variability was due to accumulating mutations during long-term clonal growth. On the basis of the presented results, it is demonstrated that somaclonal variations arise even from axillary bud explants of $R$. pseudoaca- 
cia. Theoretically, such explants are supposed to maintain clonal fidelity (Ahuja 1987; Wang and Charles 1991; Rahman and Rajora 2001). Our results suggest that microsatellite technique can be successfully used to assess genetic variations in micropropagated plants. It also demonstrates that genetic integrity of micropropagated plants should invariably be confirmed before transferring hardened plants to the field.

\section{Acknowledgements}

The work was financially supported by the Ministry of Science and Higher Education as a research grant and Trees4Future project.

\section{References}

Ahuja A. 1985. In vitro shoot differentiation in Eucalyptus citriodora Hook: effect of activated charcoal. Indian Journal of Forestry, 8, 340-341.

Ahuja M.R. 1987. Somaclonal variation. In: Cell and tissue culture in forestry. Vol. 1. General principles and biotechnology (eds.: J.M. Bonga, O.J. Durzan), Martinus Nijhoff Publisher, Dordrecht, The Netherlands, 272-285.

Arrillaga I. 1993. Regenerating plants from in vitro culture of black locust cotyledon and leaf explants. Hortscience, 28 (9), 942-945.

Balla I., Vértesy J. 1985. Experiences and problems related to the micropropagation of black locust. In: Symposium on In Vitro Problems Related to Mass Propagation of Horticultural Plants, Book of Abstracts II. International Society of Horticultural Science, Gembloux, Belgium.

Barghchi M. 1987. In vitro mass clonal propagation of Robinia pseudoacacia (black locust) cv "Jaszkiseri”. Plant Science, 53, 183-189.

Bindiya K., Kanwar K. 2003. Random amplified polymorphic DNA (RAPDs) markers for genetic analysis in micropropagated plants of Robinia pseudoacacia L. Euphytica, 135, 41-47.

De Klerk G. J., Van der Krieken W., De Jong J. C. 1999. The formation of adventitious roots: new concepts, new possibilities. In Vitro Cellular and Developmental Biology - Plant, 35, 189-199.
Dumas E., Monteuuis O. 1995. In vitro rooting of micropropagated shoots from juvenile and mature Pinus pinaster explants: influence of activated charcoal. Plant Cell Tissue and Organ Culture, 40, 231-235.

Enescu V., Jucan A. 1985. Problems of the in vitro micropropagation of black locust (Robinia pseudoacacia L.). In: New Ways in Forest Genetics. Proceeding of the 20th Canadian Tree Improvement Association Meeting, Quebec (eds.: F. Caron, A.G. Corriveau, T.J.B. Boyle), 179-184.

Garrido G., Guerreo J.R., Cano E.A., Acosta M., Sánchez-Bravo J. 2002. Origin and basipetal transport of the IAA responsible for rooting of carnation microcuttings. Physiologia Plantarum, 114, 303-312.

Goto S., Thakur R.C., Ishii K. 1998. Determination of genetic stability in long-term micropropagated shoots of Pinus thunbergii Parl. using RAPD markers. Plant Cell Reports, 18 (3/4), 193-197.

Ishii K., Moran G.F., Bell J.C., Hartney V. 1987. Genetic stability examination of micropropagated radiata pine (Pinus radiata) using isozyme assays. Journal of Japanese Forest Society, 69 (12), 487-488.

Jackson A.L., Chen R., Loeb L.A. 1998. Induction of Microsatellite instability by oxidative DNA damage. Proceedings of the National Academy of Sciences of the United States of America, 95 (21), 12468-12473.

Li Y.C., Korol A.B., Fahima T., Beiles A., Nevo E. 2002. Microsatellites: genomic distribution, putative functions, and mutational mechanisms: a review. Molecular Ecology, 11, 2453-2465.

Lian C., Oishi R., Miyashita N., Hogetsu T. 2004. High somatic instability of a microsatellite locus in a clonal tree, Robinia pseudoacacia. Theoretical and Applied Genetics, 108, 836-841.

Major A., Malvolti M.E., Cannata F. 1998. Comparison of isozyme and RAPD variability of black locust (Robinia pseudoacacia) clones selected for silivicultureal objectives. Journal of Genetics and Breeding, 52, 49-62.

Martin K.P., Pachathundikandi S.K., Zhang C.L., Slater A., Madassery J. 2006. RAPD analysis of a variant of banana (Musa sp.) cv. Grande naine and its propagation via shoot tip culture. In Vitro Cellular and Development Biology - Plant, 42 (2), 188-192. 
Modgil M., Mahajan K., Chakrabarti S.K., Sharma D.R., Sobtii R.C. 2005. Molecular analysis of genetic stability in micropropagated apple rootstock MM106. Scientia Horticulturae, 104 (2), 151-160.

Murashige T., Skoog F. 1962. A revised medium for rapid growth and bioassays with tobacco tissue cultures. Physiologia Plantarum,15, 473-497.

Pan M.J., Staden J. 1998. The use of charcoal in in vitro culture - A review. Plant Growth Regulation, 26, 155-163.

Rahman M.H., Rajora O.P. 2001. Microsatellite DNA somaclonal variation in micropropagated trembling aspen (Populus tremuloides). Plant Cell Reports, 20 (6), 531-536.
Rédei K., Keserủ Z., Rásó J. 2013 Early evaluation of micropropagated black locust (Robinia pseudoacacia L.) clones in Hungary. Forest Science and Practice, 15 (1), 81-84.

Wang P., Charles A. 1991. Micropropagation through meristem culture. In: Biotechnology in Agriculture and Forestry 17. High-Tech and Micropropagation I (ed.: Y.P.S. Bajaj), Springer-Verlag, Berlin.

Zhang J., Liu Y., Wang H. 2007. Micropropagation of Black Locust (Robinia pseudoacacia L.). In: Protocols for Micropropagation of Woody Trees and Fruits (eds.: S.M. Jain, H. Häggman), Springer, 193-199. 